\title{
Discourse of Development
}

\section{Zahid Shariff}

The assumption that people were to be given theatre was of course in keeping with the government fiction that people were to be given development particularly if they behaved themselves. (Wa Thiong'o, 1986:41)

Despite our short history, the norms of scholarship in Pakistan have already become well entrenched: the grooves already seem so deep that digging ourselves out of them may present some difficulties. (One example of that in the social sciences generally, and political science and history in particular, is the retelling of the major historical events and noting major trends without offering any remarkably new interpretations). The need, in other words, of newer and different understanding of where we are and how we got there is considerable. One purpose of introducing Escobar's (1997) Encountering Development and related materials is to offer an opportunity to get out of these academic ruts. Specifically, two exits are simultaneously provided by Escobar; one lets us interrogate the dominant narrative of development, and the other enables us to consider the possibilities that postmodernism opens up. He applies the latter to the former, which is an uncomplicated way to make what is valuable in postmodernism clear and accessible. (In what follows, the numbers in parenthesis refer to pages in Escobar's work).

Perhaps an appropriate way to introduce postmodernist analysis is to acknowledge that observation is not possible without observers; when taken seriously, its implications are profound. An equally relevant insight is that the criteria for evaluation are not separate from the phenomena to which they are applied; the two are related. Postmodernists "respond to normative claims of others by displaying the processes of thought, writing, and power on which those very normative claims are based" (Cahoone, 1996: 15-16). Furthermore, there is no independent reality out there that can be discovered by neutral observers; instead, "discourse is the process through which social reality comes into being " $(39)^{1}$.

\footnotetext{
${ }^{1}$ Application of postmodernist analysis, it has often been noted, leads to ambiguous, even contradictory, results. That is reflected in the work of two prominent Pakistani scholars in the United Kingdom. Akbar Ahmed believes, according to Gerholm (1994:209), that since "postmodernism hinges on the loss of faith in metanarratives, i.e., orthodoxies, ideologies, complete answers and total explanations," Islam "stands a better chance in the West, and perhaps world-wide.” Ziauddin Sardar, on the other hand,
} 
The considerable power of some concepts, and the practices associated with them, lies in our diminished ability to notice their presence. Our taking them for granted makes it much harder to notice that there was a time when they were not around. That appears to be true in case of what is now the well-entrenched division of the world into modern or developed, on the one hand, and underdeveloped or developing, on the other. A considerable part of life in the South ${ }^{2}$ appears to be focused on development: are the public policies promoting it, do certain proposals detract from it, do the appropriate attitudes and cultural values support or hinder it, how close is the country getting to those that are believed to be already developed? Few issues, in other words, are as central to our intellectual commitments, governmental policies, and political rhetoric as development. But it was not always so; development's history is remarkably short.

In the period between the two World Wars, a certain way of understanding was created and put in place that established "a connection between the decline of the colonial order and the rise of development" (26). When the former colonies began to be collectively called the Third World, ${ }^{3}$ the power of the discourse of development to locate, explain, and evaluate peoples and countries grew until it became virtually the only, or at least the dominant, way in which the Third World was seen by the First World, and the way it began to see itself. The globe which had previously been divided into the imperial powers and their colonial possessions was now sorted into the First, Second, and Third Worlds; and such sorting ranked these countries accordingly, with advancement, civilization, and progress associated primarily with the First World. Escobar reminds us that "these concepts did not exist before 1945" (31). He tells the story of how such a discourse and the associated practices emerged, and what were their consequences.

From the works of Michel Foucault and Edward Said, Escobar distills some significant postmodernist insights. Development, in his analysis, emerged not from material conditions (or the "reality" of poverty, hunger,

suggests that "postmodernism is an oblique attack on all fundamentalisms, i.e., on all convictions that there is an absolute truth... The obliqueness lies in its readiness to tolerate foreign fundamentalists. By doing that, relativism de facto states that there is no absolute truth. And if postmodernists and other relativists do tolerate such extravagant claims when they come for others, it is because they themselves know better" (Gerholm, 1994:210).

${ }^{2}$ As opposed to North, that is. This terminology is widely believed to be preferable to such categories as developed and developing, or First, Second, and Third worlds.

${ }^{3}$ I am aware that several events make Third World as a category highly questionable. I will, however, continue to use it because Escobar has chosen to do so. 
poor health, etc.) but from regimes of representation and recursive practices that constructed images and identities from which emerged national plans and policy interventions. That it occurred in specific ways, at a particular time, and with the backing of a variety of resources, is made explicitly the focus of considerable attention. Indeed, our unquestioning acceptance of development as a yardstick for our progress, construction of knowledge, distribution of resources and prestige, and historical change reveals its considerable and pervasive power.

Escobar does not provide a one-sentence definition of development, but the broad elements that it is based on are hard to miss. It seems to me that it is the gaze that sees human societies in a comparative and relational context. One set of countries and peoples are (a) viewed as less (advanced, developed, civilised) in some cumulative or expansive sense than others (developed, Second or First Worlds), (b) in need of help, which is available from developed countries, and (c) in transition from their present condition to one that exists in developed areas. Development became after World War II the dominant aspect of the relationship between the United States and the major former colonial powers, on the one hand, and the Third World, on the other.

\section{Being Less}

After the war, the United States as the only superpower provided very generous support to Europe but relatively insignificant amounts to the other continents. Europe was to be reconstructed while the Third World was to be developed. Until then the potential of the "natives" was thought to be severely limited; colonial rule could not survive without this and related assumptions that collectively are referred to by Aijaz Ahmed (1996) as "inferiorisation." But almost as soon as colonial rule ended, the people who had been living under it were found to be in need of development. Escobar quotes President Harry Truman's "fair deal" speech of January, 1949: "More than half the people of the world are living in conditions approaching misery... Greater production is the key to prosperity and peace. And the key to greater production is a wider and more vigorous application of modern scientific and technical knowledge" (3). Such an orientation gathered momentum as first the World Bank and then the United States Agency for International Development (US AID) as well as the International Monetary Fu8nd (IMF) got off the ground with considerable enthusiasm.

Escobar notes that in 1950 the World Bank's mission to Columbia, the first of its kind, interpreted its "terms of reference as calling for comprehensive and internally consistent program... Only through a generalized attack throughout the whole economy on education, health, 
housing, food and productivity can the vicious circle of poverty, ignorance, ill health and low productivity be decisively broken" (25). In undertaking this effort, "Columbia would not only accomplish its own salvation, but would at the same time furnish an inspiring example..." How could such astonishing confidence and the sweeping set of interventions that it called for acquire legitimacy and spread quickly? By investing heavily in it. Besides the funding for international aid (which, while small in relation to the Marshall Plan for Europe, was significant in the context of countries with low incomes), the discourse of development was very well funded and launched from many sites: universities, research centres, and such powerful international organisations as the United Nations, World Bank, and IMF. Incentives were put in place for supportive research and publications, as well as grants for education. The prospects for attractive careers, especially for economists, also helped in disseminating it. The media and Hollywood contributed significantly to the construction of those images. In addition to these, interactions and transactions among unequal parties produced, as unequal exchanges virtually always do, predictable results.

A major, perhaps more accurately, the only characteristic of the former colonies that entered the discourse of development was their deficiencies, of which poverty was preeminent but others (having to do with education, health, housing, etc.) were also included. Within a short period of time poverty "brought into existence new discourses that shaped the reality to which they referred" (24). It is not entirely surprising that the gaze of observers from affluent countries should focus on what is one of the most visible differences between their own surroundings and the Third World. But these differences here, as in so many other spheres, were not mere curiosities to be noted or admired; they were of a particular kind; and they drew attention exclusively to what the Third World lacked. To observe the absence of some useful trait or resource in an area or among a people is one thing, to define an area or people by reference to some deficiency is quite another. It was on this totalising definition that the regimes of representation were built. "Reality" was thus "colonised by the development discourse" (5).

How does one understand the propensity of these observers to see in such an extraordinarily selective fashion? What were their motivations? They were many and complex to be sure, but they are not beyond comprehension. It is easy, in these times, to get too comfortable with cynicism. It is worth nothing then that the desire to bring the good life one enjoys to others one believes are less fortunate is not in itself an exploitative or evil emotion, even if it is condescending. In addition to that, other forces were also at work. Shoring up the extended and far-flung borders of the Cold War involved making communism less attractive by trying to reduce poverty. Circling the 
Soviet Union with the U.S. - inspired military alliances was yet another consideration. Access to resources and markets played an important role as well. These motives took root and flourished in what Said (1978) has called an Orientalised world: white man's burden being borne in an infantalised Third World.

\section{Getting Help}

The help that was offered soon acquired a pattern, i.e., repetitive and formulaic ways of "solving" the problems of deficient societies. It had mostly to do with scientific techniques, capital, and cultural values. It may now appear to be a strange coincidence that what the Third World was thought to be in need of turned out to be exactly what the First World could supply! But the discourse of development then was too overwhelming to allow space for such ironies to be frequently noticed. In any case, even here some problems, not fully explored by Escobar, were encountered. When scientific knowledge was viewed as technology, its transfer was limited either by patent rights or future threats of competition. Khor (1996:18) reports that "a proposed United Nations code of conduct on technology transfer to help the Third World countries build up their own technological capabilities was scuttled, and in its place the trade-related intellectual property rights of global companies were given protection under GATT.” The supply of capital was reduced by the inability in many instances to provide reasonable collateral and/or assurances of repatriation. Nevertheless, it was to the early foreign aid projects, which included soft money loans, that can be traced the current debt trap of the Third World countries. Cultural traits also were often fond to be impediments to development, and since they proved to be even more formidable a problem, help consisted of technical assistance, institution building, and exposure of many (current and future) professionals to American higher education.

It was help that hurt. A basic assumption was made that what preceded development or what it would replace was either a void or some unpleasant phenomena. The past and present were not to be understood or appreciated; they were to be overcome. In Latin America, the United States took upon itself the right to intervene in "weaker, darker, poorer countries" (28). Upon arrival in a Third World country, Lauchlin Currie, who was on another World Bank mission, could only see "problems, darkness, chaos" (56). As development proceeded, the farmers in a Colombian village began "to interpret their lives before the programs as filled with ignorance and apathy" (51). A development economist found the Third World caught in a "vicious circle of poverty": lack of food, ill health led to low work capacity, which generated low incomes, and that in turn brought one back to lack of food. A prominent West India development economist, W. Arthur Lewis, 
recommended that the traditional elements be replaced by "modern" ones. He seemed neither perturbed by his discounting of Third World cultures nor by his unabashed acknowledgment that development would increase income inequalities. These lop-sided perceptions ignored such positive cultural and economic norms in the third World as community ties, frugality, and sufficiency.

Also ignored was the colonial context of development and its contemporary resurgence.

Colonialism is making a comeback. For centuries, the governments and corporations of the industrial nations, backed by military power, exploited the resources and markets of the poorer countries. The determination of these countries to recapture control of their resources and impose policies that favored domestic over foreign interests spurred the anti-colonial struggles that culminated in independence for much of Latin America, Africa and Asia. Now the former colonial powers are in the process of regaining the right of transnational companies to dominate the economies of the former colonies, this time through trade agreements. (Khor, 1996:17)

Such agreements, together with privatisation, NGOs, and the growing influence of international organisations reduce the ability of the Third World governments, and provide the neo-liberal context of contemporary development.

\section{Being Developed}

Facts are not discovered as much as they are created, and what enables their creation are labels and categories of analysis that serve as receptacle for them. The choice is never between labels or no labels - since unmediated understanding of the world is not possible --, but whose labels and analysis will be relied on. Clearly the discourse of development emerged within the Orientalist framework.

That discourse did not include evidence or proof of the First World's developed status as much as it assumed it; most vividly it surfaced in relation to the Post-colonial Other. "It would be the task of the white father to introduce the good but backward Third World people into the temple of progress" (158). Similarly, the change that had to occur required "unprecedented action carefully guided by the experts of the West" (159).

It would be absurd to argue that the First World was not aware of its own imperfections since a large and growing literature focuses on them. 
It would be just as absurd to deny that in the discourse of development it was the imperfections, more accurately the pathologies, of exclusively the Third World that were exhaustively displayed, scrutinised, and explained. The contrast with the First World - - sometimes explicit, often implied - suggested an unmistakable preference for it. In that discourse the implications of unequal exchange among parties surfaced fully, along with large doses of paternalism and condescension.

Not much elaboration is necessary of the frequent images in "devspeak" of the First World as a model for others to follow since we are no strangers to the ethnocentricities of others. These images project the experience of a specific group of people and countries (the First World) as the norm for all the rest, make them the measure of every one else's progress, and lend such change an aura of scientific neutrality. It is from the positionality of both the developing and the developed countries that their names, categories, and hierarchies are derived. Whatever caveats may be offered when questioning whether development equals Westernisation, the indicators and measures of the former are clearly drawn from selective aspects of life in the US and northern Europe; not surprisingly per capita income remains prominent among them while family stability does not. Escobar calls it the hegemonic form of representation.

The prescriptions for moving that First World model, however, changed with time. At one time - - roughly between 1950 to 1980 - -, the emphasis on a cohesive and integrated "attack" on the Third World's problems was strong. With the election of Ronald Reagan as U.S. president, the donor agencies - - from the US AID to the World Bank and the IMF - began to insist on privatisation, free trade, and smaller government.

\section{Development's Results}

The grip of development on our thinking is so strong that I sense the impatience of the reader in wanting answers to questions that have over time become pressing. It is at least naive, isn't it, to argue that the World Bank, the UN, or the United States "created" poverty in certain parts of the world; wasn't it there to start with? (Perhaps one should pause and take note of that impatience, for that too reflects the power of development). My reading of Escobar suggests that what the primary focus on poverty amounts to is using up most of the space on the canvas with shapes and colours so damaging that there is virtually no space left for different shapes and colours. It does not allow the raising of such questions as, how have the market forces contributed to the spread of poverty? If the major paintings of my features are going to be crafted by those who see only my scars and warts, what would one expect the viewers to think of me? And as I continue to see myself so represented, is 
there really any serious doubt about what over time my self-perception is likely to become? Other issues are vital as well. "Developmentalisation of the Third World" required that other attributes of the "natives" that interfered with what became the ritual of finding problems with a view to fixing them be largely suppressed; indeed, "culture" entered the discourse of development almost exclusively as an impediment to development. When features that may clutter up the canvas were not being ignored, they were not thought to exist at all. Before development there was nothing; that amounted, for instance, to denying the value in many Third World cultures on bonds of community, labour-intensive productive processes, and care and respect for the old. These considerations, often overlooked, are not expected to deny that

development might have benefited people at times. It is to emphasise that the work of development institutions has not been an innocent effort on behalf of the poor. Rather, development has been successful to the extent that it has been able to integrate, manage, and control countries and populations in increasingly detailed and encompassing ways. (46-7)

Focus on poverty as the defining characteristic of the Third World is made worse, if that was possible, by conjuring up a monolithic version of it. That the poor distributed over several continents are not homogenous appears not to be fully integrated into the discourse of development. Thus "a squatter in Mexico City, a Nepalese peasant, and a Tuareg nomad become equivalent to each other as poor and underdeveloped" (53). Such sweeping generalisations reminded me of an event that Wa Thiong'o (1986:40) recorded. A "white lady had her nose bloodied by a black actor after she had called him a black bastard. The police came but in the identification parade she could not make out one African face from another."

As one turns to the effects of development, the evidence appears grim. Consider first gender issues. Before the development programmes were introduced, women were in many areas well integrated into work and productive life; work roles merged with family responsibilities; and much of what was produced was for use, not exchange. In those settings, women often participated fully in the economy of the community and household. As much as 50 per cent of the world's food produced for direct consumption was estimated by the Food and Agricultural Organization (FAO) to be the outcome of women's efforts. Development changed all that. The US AID and FAO trained men in agriculture, and women in home economics. Production by more efficient methods (e.g., tractors), and for exchange, reinforced gender segregation since it was men who were selected to drive tractors and grow cash crops. Farmers, in other words, were "replaced by energy- and capital-intensive machinery, and diversified food production for 
local communities...[was] replaced by export monoculture" (Norberg-Hodge, 1996:19). A recent Pakistani study of rural women confirms these views. Khalid's (1995:65) conclusions are unambiguous: "It seems to us that modernisation, as currently understood and promoted by national and international agencies, tends to increase the burden on women physically, emotionally and psychologically."

The results that development produced over the last half century can be summarised in figures and statistics. Between 1979 and 1982, the food available to poor people fell by 30 per cent; during the same period, more than $\$ 30$ billion was paid than was received in new lending; tropical forests are being rapidly cut down (212-213). A particularly devastating result of development was the increase in income inequality. Korten relying on United Nations figures showed that

" 20 per cent of the world population who live in the richest countries receive 82.7 per cent of the income." The poorest 20 per cent get 1.4 per cent of world income. The combined incomes of the top 20 per cent are sixty times larger than those of the bottom 20 per cent.

Furthermore, this gap has doubled since 1960, when the top 20 per cent enjoyed only thirty times the income of the bottom 20 per cent. And the gap continues to grow.

The figures actually understate the true inequality in the world because they are based on national income accounts rather than actual individual incomes. If we take into account the very rich people who live in poor countries and the very poor who live in rich countries, the incomes of the richest 20 per cent of the world's people are approximately 140 times those of the poorest 20 per cent. (Korten, 1961:16)

Escobar carefully notes these economic statistical trends but his emphasis is clearly on culture, representation, and influence. The "counting" that he is interested in

reflects the crafting of subjectivities, the shaping of culture, and the construction of social power - including what these figures say about surplus material and symbolic consumption in those parts of the world that think of themselves as developed. Not the perverse reading, finally, of the International Monetary Fund - insisting on "austerity measures" for the Third World, as if the majority of people in the Third World had known anything but material 
austerity as a fundamental fact of their daily existence -- but a renewed awareness of the suffering of many, of the fact that" [to quote Ashis Nandy] the modern world including the modernised Third World, is built on the suffering and brutalization of millions (213).

Another aspect of this shaping of cultures is explored by NorbergHodge (1996:19-20). She too needs to be quoted at length.

Advertising and media images exert powerful psychological pressures to seek a better, more "civilized" life, based on the urban, Western consumerist model. Individual and cultural self-esteem are eroded by the advertising stereotypes of happy, blond, blue-eyed, clean Western consumers. If you have been a farmer, or are dark-skinned, you are made to feel primitive, backward, inferior. Partly as a consequence, women around the world are now using dangerous chemicals to lighten their skin and hair, and the market is growing for blue contact lenses in such places as Bangkok, Nairobi and Mexico City. Many Asian women who can afford it have had their eyes operated on to make them appear more Western.

\section{Conclusion}

This concluding part is divided into two; the first is devoted to Escobar's remedies, and the second to some evaluative comments.

Escobar's remedies flow from his analysis. Since development is destructive, the "need to unmake and unlearn development" (223) is paramount. Instead of alternative development strategies, he argues, we need alternatives to development. Grand, macro-level alternatives that apply to all situations are clearly inappropriate. It is through ethnographic studies of hybrid cultures that take local settings and their meanings seriously that will allow the subaltern to speak. Intellectual work in the future may link popular culture with political struggles, "take up the questions of social justice and of the construction of new social orders from the vantage point of postmodernity"; and "the formulation of the question of cultural identity in nonessentialist ways" (218). These may open up "spaces for destabilizing dominant modes of knowing" (223).

The unqualified denigration of Third World cultures is probably the greatest harm that development inflicts. It does so by viewing them in a monolithic fashion, and finding virtually nothing redeemable about them; on the other hand, the First World is valourised without any hint of its imperfections. Such a verdict is harsh and unwarranted. Others, more willing 
to look for something positive in the Third World, have found it. Pye (1985:334), for instance, argued that the "most constructive aspect of the psychology of dependency [in Asia] is its potential for building cooperation and strong bonds for teamwork. Acceptance of conformity and commitment to the group makes it easy to suppress egotistical assertiveness and to work smoothly with others."

When economists are sent to an area, we should not be surprised by their conclusion that the problems they are able to identify are economic and the remedy is economic growth. In a broader sense, the First World observers are expected to find those characteristics of the Third World that distinguish it and set it apart; from there the need for massive interventions seem natural. "Development proceeded with creating abnormalities" (41). The fundamental problem of the Third World, it would seem, is that it is the Third, not the First, World.

An attempt to evaluate Escobar's work should probably take into account what existed before the publication of Encountering Development. The ideology of development was beyond serious challenge. No one had argued so seriously and impressively that it had inflicted considerable amount of economic damage to the Third World, and that it had gone a long way toward subverting cultural norms and identities. Many Third World students that I came into contact with in the United States, and most of them in Pakistan as well, have learned to disparage, or remain ignorant about, the Third World's cultural heritage. Through their education, media, and films their attraction for the First World, in contrast, continues to grow. "It is the final triumph of a system of domination," writes Wa Thiong'o (1986:20), "when the dominated start singing its virtues."

Escobar's singular achievement is to provide a counter-narrative to such a prevailing orthodoxy. A note of dissent and an antidote to vestigial thinking that was sorely lacking is now available. He minded a variety of disciplines to present an integrated, new perspective on development. He makes a plausible case that development is responsible for damage to the Third World on a vast scale.

I also believe that his understanding of development did not sufficiently include some changes in emphasis over the last fifty years, the period that he explores. He noted the "death and recasting of development economics" (57) in the 1980s. His readers would have benefited from more discussion of how serious were those changes. Greater sensitivity to periodisation and a more nuanced understanding of some changed emphasis would have enriched his work further. Rahim (1998:7), for example, refers to a World Bank study which concluded that "investment has declined after 
liberalisation in every case and had never recovered" (emphasis added). Sachs (1998:15) appears to agree: "The problem is that the IMF has become the Typhoid Mary of emergency markets, spreading recession in country after country."

His suspicion of grand narratives and preference for local action is entirely consistent with his findings. They also fit nicely with his grounding in anthropology as well as postmodernism. One size, it is often true, does not fit all. I wish, however, he had given some thoughtful attention to some dangers that lurk in local settings also. The most obvious one, it seems to me, is the prospect of local tyrants being freed from some humane criteria that are often more visible at the national levels (through the constitutions, laws, other norms). It is true that such criteria have often not been applied with any great enthusiasm, but the potential is probably greater there than at local levels. I have argued elsewhere (Shariff, 1995) that a variety of str4uctural incentives run more in the direction of the national government assuming responsibility for income redistribution policies than is likely among smaller sub-national jurisdictions. Similarly, if the multi-national corporations are the menace that he claims, they are more likely to be controlled or regulated at the national level; at the sub-national levels they are quite skilled in inducing such governments to compete with each other in offering them incentives.

All in all, Escobar has made the issue of development more lively and susceptible to diverse meanings. That is an impressive feat. 


\section{References}

Ahmed, Aijaz. 1996. In Theory. London: Verso.

Cahoone, Lawrence E. 1996. “Introduction.” In Cahoone (ed.). From Modernism to Postmodernism. Cambridge, Mass.: Blackwell, 1-23.

Escobar, Arturo. 1995. Encountering Development. Princeton, NJ: Princeton University Press.

Gerholm, Tomas. 1994. "Two Muslim Intellectuals in the Postmodernist West: Akbar Ahmed and Ziauddin Sardar.” In Ahmed and Hastings Donnan (eds.). Islam, Globalization and Postmodernity. London and New York: Routledge.

Khalid, Javeria. 1995. "Rural Women, Poverty and Feminist Research Methodology." In Nighat Saeed Khan, Rubina Saigol, and Afiya Sherbano Zia (eds.). Aspects of Women in Development, Lahore: ASR, 58-65.

Khor, Martin. 1996. “Colonialism Redux." The Nation (New York), July $15 / 22,17-19$.

Korten, David C. 1996. “The Limits of the Earth.” The Nation (New York), July 15/22, 14-17.

Norberg-Hodge, Helen. 1996. "Break Up the Monoculture." The Nation (New York), July 15/22, 20-23.

Pye, Lucien. 1985. Asian Power and Politics. Cambridge, Mass.: Harvard University Press.

Rahim, Sikander. 1998. "Agreement with IMF - I. A Better Alternative." The Nation (Lahore), November 15, 7.

Sachs, Jeffery D. 1998. "Rule of the Ruble." The New York Times, June 15 (an op-ed. Piece).

Said, Edward. 1978. Orientalism. New York: Vintage Books.

Shariff, Zahid, 1995. "Inequality and Government." In William M. Dugger (ed.). Inequality. Westport, Conn.: Greenwood Press, 153-166.

Wa Thiong'o, Ngugi. 1986. Decolonizing the Mind. Nairobi: Heineman Kenya. 